\title{
Growth hormone and aging: A challenging controversy
}

\section{Andrzej Bartke}

Geriatrics Research, Departments of Internal Medicine and Physiology, Southern Illinois University School of Medicine, Springfield, IL, USA
Correspondence: Andrzej Bartke Geriatrics Research, Departments of Internal Medicine and Physiology, Southern Illinois University School of Medicine, P.O. Box 19628, Springfield, Illinois 62794-9628, USA

Tel +12175457962

Fax +I 2175458006

Email abartke@siumed.edu

\begin{abstract}
Although advanced age or symptoms of aging are not among approved indications for growth hormone (GH) therapy, recombinant human $\mathrm{GH}(\mathrm{rhGH})$ and various GH-related products are aggressively promoted as anti-aging therapies. Well-controlled studies of the effects of rhGH treatment in endocrinologically normal elderly subjects report some improvements in body composition and a number of undesirable side effects in sharp contrast to major benefits of GH therapy in patients with GH deficiency. Controversies surrounding the potential utility of $\mathrm{GH}$ in treatment of a geriatric patient are fueled by increasing evidence linking GH and cancer and by remarkably increased lifespan of GH-resistant and GH-deficient mice. Conservation of cellular signaling mechanisms that influence aging in organisms ranging from worms to mammals suggests that at least some of the results obtained in mutant mice are applicable to the human. We suggest that the normal, physiological functions of GH in promoting growth, sexual maturation and fecundity involve significant costs in terms of aging and life expectancy. Natural decline in GH levels during aging likely contributes to concomitant alterations in body composition and vigor but also may be offering important protection from cancer and other age-associated diseases.
\end{abstract}

Keywords: growth hormone, longevity, cancer, anti-aging therapies, mutant mice

\section{Introduction}

Last year, Liu and colleagues (2007) reported results of meta analysis of findings from a series of 18 studies of the use of recombinant human growth hormone (rhGH) in healthy elderly and concluded that the literature "to randomized, controlled trials evaluating GH therapy ... suggest that it is associated with small changes in body composition and increased rates of adverse events" and that "based on this evidence, GH cannot be recommended as an anti-aging therapy." Proponents of the use of rhGH as antiaging therapy promptly placed on the internet a lengthy rebuttal entitled "Analysis of faulty data yields inaccurate results" (A4M 2007). The contrast between these two communications illustrates the intensity of a long-standing controversy concerning the role of $\mathrm{GH}$ in the control of aging and the potential utility of $\mathrm{GH}$ as an anti-aging agent. The purpose of this article is to briefly summarize the findings that prompted this controversy, highlight some recent reports pertinent to this topic and propose an explanation for the existence of both detrimental and beneficial effects of GH on life expectancy, age-related diseases and functionality during different stages of life.

\section{Age-related decline in $\mathrm{GH}$ release and its functional implications: The somatopause}

Growth hormone levels in circulating blood are high early in life, corresponding to the period of rapid somatic growth, and begin to decline soon after attainment of adult body size and full physical and reproductive maturation. This decline continues during adult life and aging and consequently plasma GH levels in elderly individuals are much 
lower than in young adults. Age-related decline in GH levels is very well documented, consistent across different mammalian species and primarily due to reduced hypothalamic secretion of GH-releasing hormone (GHRH) with consequent decline of $\mathrm{GH}$ biosynthesis and release by the anterior pituitary (Sonntag et al 1980; Glustina and Veldhuis 1998; Kuwahara et al 2004; Frutos et al 2007). This, in turn, leads to a reduction in circulating levels of insulin-like growth factor 1 (IGF-1), the key mediator of GH action (Goodman-Gruen and Barrett-Connor 1997; Maggio et al 2006). Age-related decline in the activity of the somatotropic axis (GHRH, GH and IGF-1) has been termed "somatopause" in analogy to the menopause and andropause, the age-related decline in gonadal function and plasma levels of sex steroids in women and men. Because some of the symptoms of aging including decrease in muscle mass, increased adiposity, reduced libido and energy resemble symptoms of adult GH deficiency, it is reasonable to conclude that somatopause accounts for or contributes to the development of many of these symptoms. This argument is strengthened by the well-documented role of declining levels of sex steroids in the morphological and functional changes that accompany aging.

\section{Can GH therapy prevent or perhaps even reverse aging?}

The landmark study of Rudman and colleagues (1990) reported that 6 months of treatment of men over 65 years of age who have low levels of plasma IGF-1 with rhGH reduced adiposity, increased muscle mass, increased bone mineral density in some of the examined sites of the skeleton and improved general well-being. These results elicited enormous general interest by raising the possibility of using hormonal replacement therapy to slow down, halt or perhaps even reverse aging, or at least some of its symptoms. These exciting possibilities were consistent with well-documented and often quite dramatic beneficial effects of GH treatment in patients with GH deficiency (Baum et al 1998; Shalet et al 2006; Arwert et al 2006) and with the ability of GH therapy to ameliorate age-related changes in metabolic characteristics, brain vascularity and cognitive function in old rats (Ramsey et al 2004; Sonntag et al 2005b; Groban et al 2006). However, studies conducted after the report of Rudman and colleagues (1990) indicated that treatment of endocrinologically normal healthy elderly individuals with rhGH produces generally small improvements in body composition along with a number of undesirable side effects including arthralgias, edema, carpal tunnel syndrome, insulin resistance and possibly also diabetes (Papadakis et al 1996; von Werder 1999; Blackman et al 2002; Liu et al 2007). Thus it appears that effects of GH replacement in young or middle-aged adults who developed GH deficiency as a result of head trauma, pituitary tumors and/or treatment of cranial tumors with surgery or irradiation are difficult to reproduce in elderly individuals in which $\mathrm{GH}$ levels are low due to age-related decline in the hypothalamic "drive" of somatotroph function. It is also difficult to compare the results of randomized placebo-controlled studies to open label and case studies and there is considerable disagreement about rhGH dose levels that may have optimal risk:benefit ratio in elderly subjects. Additional large, long-term studies are needed to arrive at firm conclusions about the potential usefulness of $\mathrm{GH}$ for treatment of specific age associated changes such as an increase in visceral obesity or as an anti-aging agent.

In the context of the ongoing controversy about the use of GH in geriatric "anti-aging" medicine, it should also be mentioned that the clinical use of rhGH is currently approved in the US only for treatment of GH deficiency, idiopathic short stature and HIV/AIDS.

\section{Does GH normally act to promote rather than prevent aging?}

Mice with mutations that cause GH deficiency or GH resistance live longer than their genetically normal siblings (Table 1). This includes animals with targeted disruption of the $\mathrm{GH}$ receptor gene that blocks $\mathrm{GH}$ actions, ie, produces complete $\mathrm{GH}$ resistance, the so-called Laron dwarf mice (Coschigano et al 2003), Ames dwarf and Snell dwarf mice, which have defects of anterior pituitary development leading to the absence of $\mathrm{GH}$, prolactin and thyrotropin (BrownBorg et al 1996; Flurkey et al 2001) and Little mice with isolated $\mathrm{GH}$ deficiency due to mutation of the receptor for hypothalamic GH-releasing hormone (Flurkey et al 2001). The increased longevity in these mutants is striking, ranging from $25 \%$ to over $60 \%$ and readily reproducible, present in both genders and not limited to a particular inbred or heterogeneous genetic background or diet formulation (Coschigano et al 2003; Bartke and Brown-Borg 2004a; Bartke et al 2004b; Bartke 2006; Bonkowski et al 2006b). Importantly, these long-lived mutants exhibit numerous indices of delayed aging and maintain youthful appearance, vigor and cognitive abilities at the age at which normal animals exhibit significant physical and functional decline (Flurkey et al 2001; Silberberg 1972; Kinney et al 2001a, 2001b). The increased "healthspan" of these mutants also includes reduced incidence and delayed onset of neoplastic disease, 
Table I Mutant mice with reduced somatotropic (GH/IGF-I) signaling and extended longevity

\begin{tabular}{|c|c|c|}
\hline Mutation & Effects on somatotropic signaling & Reference \\
\hline $\begin{array}{l}\text { Ames dwarf; mutation of Prophet of pituitary } \\
\text { factor I (Propl); Prop If }\end{array}$ & $\begin{array}{l}\text { Failure of somatotroph differentiation; } \\
\text { GH deficiency }\end{array}$ & Borg et al 1996 \\
\hline Snell dwarf; mutation of Pituitary factor I; Pit $\left.\right|^{d w}$ & $\begin{array}{l}\text { Failure of somatotroph differentiation; } \\
\text { GH deficiency }\end{array}$ & Flurkey et al $200 \mathrm{I}$ \\
\hline $\begin{array}{l}\text { Little; mutation of GH releasing hormone receptor; } \\
\text { Ghrhrit }\end{array}$ & GH deficiency & Flurkey et al $200 \mathrm{I}$ \\
\hline $\begin{array}{l}\text { Laron dwarf; Deletion of GH receptor/GH binding } \\
\text { protein gene; Ghr/bp -/- }\end{array}$ & $\begin{array}{l}\text { Deletion of } \mathrm{GH} \text { receptors; } \mathrm{GH} \\
\text { resistance }\end{array}$ & Coschigano et al 2003 \\
\hline Midi-mice; hypomorphic IGF-I mutation & Reduced IGF-I levels & Sell and Lorenzini 2007 \\
\hline Heterozygous for deletion of IGF-I receptor, Igfr +/- & Partial IGF-I resistance & Holzenberger et al 2003 \\
\hline $\begin{array}{l}\text { Deletion of Pregnancy associated plasma protein A; } \\
\text { PAPP-A -I- (an IGFBP protease) }\end{array}$ & $\begin{array}{l}\text { Reduced local (tissue) availability of } \\
\text { IGF-I }\end{array}$ & Conover and Bale 2007 \\
\hline
\end{tabular}

Abbreviations: GH, growth hormone; IGF-I, insulin-like growth factor- I; IGFBP, insulin-like growth factor binding protein.

the most common cause of death in laboratory mice (Ikeno et al 2003; unpublished data).

These results lead to a counterintuitive but unavoidable conclusion that the actions of GH normally released by the pituitary somehow limit life expectancy and that this is accompanied by and likely due to acceleration of the biological process of aging. The conclusion that $\mathrm{GH}$ signaling can accelerate aging and shorten lifespan is strongly supported by the reports that reduced levels of IGF-1, partial IGF-1 resistance and mutations suppressing IGF-1 signaling downstream from the IGF-1 receptor also increase longevity of mice although only in females (Holzenberger et al 2003; Sell and Lorenzini 2007; Taguchi et al 2007; Selman et al 2008). Disagreement between the reported effects of insulin receptor substrate 2 (IRS2) gene deletion on mouse longevity (Taguchi et al 2007; Selman et al 2008) is likely related to using different diets in these two laboratories (Bartke 2007, 2008). Further support of the role of IGF-1 in aging is provided by the recent findings that deletion of pregnancy-associated plasma protein $\mathrm{A}$ (PAPP-A), a protease that destroys IGF-1 binding proteins, markedly increases longevity of mice presumably by reducing local availability of IGF-1 (Conover and Bale 2007). In this context, it is of interest that transgenic mice with grossly elevated levels of GH and IGF-1 due to overexpression of different $\mathrm{GH}$ genes are short-lived and express various symptoms of accelerated aging (Bartke 2003).

\section{Phenotype of long-lived mutant mice: Tradeoffs and costs of extended longevity}

Growth hormone-resistant, hypopituitary and GH-deficient mice appear normal at birth but their postnatal growth rate is reduced, leading to markedly diminished adult size.
This is most pronounced in the Snell and Ames dwarfs that, in adulthood, weigh less than a half of the body weight of their normal siblings. Reduction in body weight of these mutants is often accompanied by increased adiposity, which is particularly striking in Ghr-/- ("Laron dwarf") and Ghrhr-/- ("Little") mice (Flurkey et al 2001; Berryman et al 2004; Bonkowski et al 2006). Interestingly, these obese animals do not exhibit symptoms of metabolic syndrome or propensity to develop type 2 diabetes. Instead, they are hypoinsulinemic and very sensitive to insulin actions (Borg et al 1995; Zhou et al 1997; Dominici et al 2002; Bonkowski et al 2006b). These paradoxical findings have been related to diminished mass of pancreatic islets (Parsons et al 1995; Liu et al 2004), and preferential distribution of fat to subcutaneous depots (Berryman et al 2004; unpublished data).

In long-lived GHRKO mice, sexual maturation is delayed and various measures of fecundity including litter size and intervals between consecutive litters are reduced in comparison to normal animals (Chandrashekar et al 1999; Zaczek et al 2002; Keene et al 2002). Female Snell and Ames dwarf mice are infertile but this is specifically due to prolactin deficiency (Bartke and Brown-Borg 2004a; Bartke 2006) rather than to reduced GH signaling. These findings could be interpreted as evidence for "tradeoffs" between somatic growth, reproductive potential and longevity. It is interesting that in comparison to the established strains of laboratory mice that have been bred in captivity for over a hundred years, ie, for many hundreds of generations, stocks of mice derived from animals recently captured in their natural environment are characterized by reduced body size, delayed puberty, small litters and enhanced longevity (Harper et al 2006). One could speculate that selection for optimal breeding performance in captivity led to GH-mediated enhancement of fecundity and 
the rate of growth and maturation at expense of accelerated aging, earlier onset of age-related disease and reduced life expectancy. Genetic manipulations and spontaneous mutations that reduce GH signaling would thus restore and exaggerate some features of the original "wild type" phenotype. Many examples of trade-offs between longevity, growth and reproduction have been provided by studies in invertebrates (Partridge et al 2005).

\section{Does the relationship of $\mathbf{G H}$ and aging discovered in mice apply to other species?}

Results obtained in natural mutant, gene knock-out and transgenic mice discussed earlier in this article demonstrate a striking negative association of somatotropic signaling and lifespan. Analysis of average longevity of mice from different strains, stocks and selected lines as well as individual animals from a genetically heterogeneous population provided evidence that this association apparently applies also to genetically normal individuals (Roberts 1961; Rollo 2002; Miller et al 2002). In these comparisons, adult body size, which can be considered a biological marker of GH actions, was negatively correlated with longevity. Similar association was reported in other species, including rats (Rollo 2002) and horses (Brosnahan and Paradis 2003) and is particularly striking in domestic dogs with small breeds and small individuals living much longer than large dogs (Patronek et al 1997; Greer et al 2007). In rats, reducing somatotropic signaling by transgenic expression of missense GH produced a modest but statistically significant increase in lifespan (Shimokawa et al 2002) but longevity of GH-deficient dwarf rats does not differ from their normal siblings (Sonntag et al 2005a). Interestingly, rats with adult GH deficiency produced by treating GH-deficient mutants with GH early in life and then discontinuing this treatment, lived longer than vehicle-injected mutants or normal controls (Sonntag et al 2005a).

It is not entirely clear to what extent the negative association of adult body size with longevity applies to the human. Pioneering studies of Samaras and his colleagues (recently summarized in a book [Samaras 2007]) provided numerous examples of short individuals living longer than tall individuals from the same population. For example, in over 3,000 professional baseball players, age at death was strongly negatively correlated with both height and weight (Samaras and Storms 2002; Samaras 2007). In contrast, some studies reported increased risk of cardiovascular disease and reduced life expectancy in short individuals (Forsen et al 2000;
Schnaider et al 2005). There is strong evidence that tall individuals have increased cancer risk (Tretli 1989; Gunnell et al 2001; Littman et al 2007), but the relationship of stature to overall mortality continues to be controversial. Data specifically concerning the effects of GH on human longevity are also inconsistent. One study reported markedly reduced longevity of individuals with congenital GH deficiency (Besson et al 2003) while other workers reported that both GH-deficient and GH-resistant subjects can reach very advanced age, are protected from cancer and, interestingly, are also protected from atherosclerosis and vascular pathology in spite of obesity and unfavorable serum lipid profiles (Krzisnik et al 1999; Laron 2005; Menezes Oliveira et al 2006; Shechter et al 2007; Shevah and Laron 2007). Discussion of genetic, lifestyle, nutritional and socioeconomical factors affecting growth, adult stature, health and longevity in the human is beyond the scope of this brief review.

Pathological hypersecretion of GH in patients with gigantism and acromegaly reduces life expectancy due to increased incidence of cardiovascular disease, diabetes and, in acromegalics, apparently also cancer (Jadresic et al 1982; Orme et al 1998). The question whether the rate of aging is affected by acromegaly has apparently never been addressed. A series of elegant studies by Sacca and colleagues (Sacca et al 1994, 2003) provided evidence that both GH deficiency and GH excess are detrimental for cardiac function in the human with GH-deficient patients benefiting from GH therapy and acromegalics benefiting from suppression of $\mathrm{GH}$ levels. Another possible reason for the complex relationship between somatotropic signaling and human longevity was provided by results of genetic studies which indicated that reduced IGF-1 levels protect from some age-related diseases but increase the risk of others (Lamberts et al 1997).

\section{Interplay of GH and aging: Current understanding and potential for anti-aging interventions}

Although much of the currently available information concerning the role of $\mathrm{GH}$ in the control of human aging is limited in scope and inconclusive and some time are conflicting, there is every reason to believe that the results of ongoing and future studies will change this situation. GH actions and control of somatic growth have already been related to aging and longevity in other mammals including rodents, carnivores and ungulates (details earlier in this article). GH has a key role in controlling biosynthesis of IGF-1 and exerts important direct and indirect actions on the secretion of insulin and on responsiveness of target tissues to insulin actions. 
A major role of IGF-1, insulin and homologous molecules in the control of longevity has been conclusively documented in organisms ranging from worms and insects to mammals, and related mechanisms influence aging of unicellular yeast. Against the background of this information, it is difficult to imagine how aging in primates or humans could prove to be free of the influence of somatotropic signaling.

How can we summarize the present understanding and use this information to suggest possible anti-aging interventions? Physiological action of the amounts of GH normally secreted by the pituitary is critically needed for growth and maturation and enhances reproductive potential but may also limit life expectancy. Somatotropic signaling can be suppressed by modest calorie restriction (Masoro 2001). Well-documented beneficial effects of calorie restriction on longevity of many species and on important predictors of life expectancy in humans (Heilbronn et al 2006; Holloszy and Fontana 2007) suggest that subtle, long-term reduction in $\mathrm{GH}$ release and/or activity may have a potential to slow aging, protect from age-related disease and increase lifespan. However, the symptoms of congenital or acquired GH-deficiency clearly indicate that severe or complete suppression of GH actions can not be recommended or even seriously considered for enhancement of human longevity.

GH levels decline during aging. This natural change in the endocrine system most likely contributes to unwelcome effects of aging on body composition, skin characteristics and functional changes contributing to the general quality of life, but at the same time may offer protection from cancer and other age-related diseases. Thus GH replacement therapy is almost certain to involve both risks and benefits. It appears likely that future research will demonstrate benefits of low-dose GH therapy in some individuals with frailty and/or sarcopenia and clearly define contraindications to $\mathrm{GH}$ therapy, for example, family history or genetic predisposition to cancer. Current debates about the use of estrogens in postmenopausal women and testosterone in elderly men and emergence of guidelines for individualized approach to sex steroid therapy allow the prediction of how responsible use of $\mathrm{GH}$ in geriatric medicine may eventually evolve.

After this article was written, Suh and colleagues (2008) described mutations of the human IGF-1 receptor which reduce cellular responses to IGF-1 and reported that in women, IGF-1 resistance is associated with shorter stature and extended longevity. These important findings provide the strongest evidence available to date that reduced somatotropic signaling can lead to increased life expectancy in the human.

\section{Acknowledgments}

Research in our laboratory and preparation of this chapter were supported by NIA (NIH) via grants AG19899 and U19 AG023122, by the Ellison Medical Foundation, the Glenn Foundation for Medical Research and by the SIU Geriatrics Research Initiative. The help of S Sandstrom and P Barnett in preparation of the manuscript is gratefully acknowledged. The author apologizes to those whose work pertinent to this topic was not cited due to limitations of the format of this article or to inadvertent omissions.

\section{References}

[A4M] American Academy of Anti-Aging Medicine. 2007. Analysis of faulty data yields inaccurate results: Thousands benefit from growth hormone replacement therapy for aging-related disorders - proven, real-world track record of benefits of adult growth hormone deficiency therapy disputes publication. A4M Official Response Statement [online]. Accessed on Oct 17, 2008. URL: http://www.worldhealth. net/news/analysis_of_faulty_data_yields_inaccurat.

Arwert LI, Veltman DJ, Deijen B, et al. 2006. Effects of growth hormone substitution therapy on cognitive functioning in growth hormone deficient patients: A functional MRI study. Neuroendocrinology, 83:12-9.

Bartke A. 2003. Can growth hormone $(\mathrm{GH})$ accelerate aging? Evidence from GH-transgenic mice. Neuroendocrinology, 78:210-6.

Bartke A, Brown-Borg PS. 2004a. Life extension in the dwarf mouse. In: Current Topics in Developmental Biology. San Diego: Academic Press, pp. 189-225.

Bartke A, Peluso MR, Moretz N, et al. 2004b. Effects of soy-derived diets on plasma and liver lipids, glucose tolerance, and longevity in normal, long-lived and short-lived mice. Horm Metab Res, 36:550-8.

Bartke A. 2006. Life extension in the dwarf mouse. In: Conn PM (ed). Handbook of models for the study of human aging. San Diego: Elsevier Academic Press, pp. 403-14.

Bartke A. 2007. Aging: All in the head? Cell Metabol, 6:153-4.

Bartke A. 2008. Impact of reduced insulin-like growth factor-1/insulin signaling on aging in mammals: novel findings. Aging Cell, 7:285-90.

Baum HB, Katznelson L, Sherman JC, et al. 1998. Effects of a physiological growth hormone (GH) therapy on cognition and quality of life in patients with adult-onset GH deficiency. J Clin Endocrinol Metab, 83:3184-9.

Berryman DE, List EO, Coschigano KT, et al. 2004. Comparing adiposity profiles in three mouse models with altered GH signaling. Growth Horm IGF Res, 14:309-18.

Besson A, Salemi S, Gallati S, et al. 2003. Reduced longevity in untreated patients with isolated growth hormone deficiency. J Clin Endocrinol Metab, 88:3664-7.

Blackman MR, Sorkin JD, Munzer T, et al. 2002. Growth hormone and sex steroid administration in healthy aged women and men: A randomized controlled trial. JAMA, 288:2282-92.

Bonkowski MS, Pamenter RW, Rocha JS, et al. 2006a. Long-lived growth hormone receptor knockout mice show a delay in age-related changes of body composition and bone characteristics. J Gerontol A Biol Sci Med Sci, 61:562-7.

Bonkowski MS, Rocha JS, Masternak MM, et al. 2006b. Targeted disruption of growth hormone receptor interferes with the beneficial actions of calorie restriction. Proc Natl Acad Sci U S A, 103:7901-05.

Borg KE, Brown-Borg HM, Bartke A. 1995. Assessment of the primary adrenal cortical and pancreatic hormone basal levels in relation to plasma glucose and age in the unstressed Ames dwarf mouse. Proc Soc for Exp Bio Med, 210:126-33.

Brosnahan MM, Paradis MR. 2003. Demographic and clinical characteristics of geriatric horses: 467 cases (1989-1999). J Am Vet Med Assoc, 223:93-8. 
Brown-Borg HM, Borg KE, Meliska CJ, et al. 1996. Dwarf mice and the ageing process. Nature, 384:33.

Chandrashekar V, Bartke A, Coschigano KT, et al. 1999. Pituitary and testicular function in growth hormone receptor gene knockout mice. Endocrinology, 140:1082-8.

Conover CA, Bale LK. 2007. Loss of pregnancy-associated plasma protein A extends lifespan in mice. Aging Cell, 6:727-9.

Coschigano KT, Holland AN, Riders ME, et al. 2003. Deletion, but not antagonism, of the mouse growth hormone receptor results in severely decreased body weights, insulin, and insulin-like growth factor I levels and increased life span. Endocrinology, 144:3799-810.

Dominici FP, Hauck S, Argentino DP, et al. 2002. Increased insulin sensitivity and upregulation of insulin receptor, insulin receptor substrate (IRS)-I and IRS-2 in liver of Ames dwarf mice. J Endocrinol, 173:81-94.

Flurkey K, Papaconstantinou J, Miller RA, et al. 2001. Lifespan extension and delayed immune and collagen aging in mutant mice with defects in growth hormone production. Proc Natl Acad Sci U S A, 98:6736-41.

Forsen T, Eriksson J, Qiao Q, et al. 2000. Short stature and coronary heart disease: a 35-year follow-up of the Finnish cohorts of The Seven Countries Study. J Int Med, 248:326-32.

Frutos MGS, Cacicedo L, Mendez CF, et al. 2007. Pituitary alterations involved in the decline of growth hormone gene expression in the pituitary of aging rats. J Gerontol A Biol Sci Med Sci, 62:585-97.

Giustina A, Veldhuis JD. 1998. Pathophysiology of the neuroregulation of growth hormone secretion in experimental animals and the human. Endo Rev, 19:717-97.

Goodman-Gruen D, Barrett-Connor E. 1997. Epidemiology of insulin-like growth factor-I in elderly men and women: The Rancho Bernardo Study. Am J Epidemiol, 145:970-6.

Greer KA, Canterberry SC, Murphy KE. 2007. Statistical analysis regarding the effects of height and weight on life span of the domestic dog. Res Vet Sci, 82:208-14.

Groban L, Pailes NA, Bennett CDL, et al. 2006. Growth hormone replacement attenuates diastolic dysfunction and cardiac angiotensin II expression in senescent rats. J Gerontol A Biol Sci Med Sci, 61:28-35.

Gunnell D, Okasha M, Davey Smith G, et al. 2001. Height, leg length, and cancer risk: a systematic review. Epidemiol Rev, 23:313-42.

Harper JM, Durkee SJ, Dysko RC, et al. 2006. Genetic modulation of hormone levels and life span in hybrids between laboratory and wildderived mice. J Gerontol A Biol Sci Med Sci, 61:1019-29.

Heilbronn LK, de Jonge L, Frisard MI, et al. 2006. Effect of 6-month calorie restriction on biomarkers of longevity, metabolic adaptation, and oxidative stress in overweight individuals: A randomized controlled trial. JAMA, 295:1539-48.

Holloszy JO, Fontana L. 2007. Caloric restriction in humans. Exp Gerontol, 42:709-12.

Holzenberger M, Dupont J, Ducos B, et al. 2003. IGF-1 receptor regulates lifespan and resistance to oxidative stress in mice. Nature, 421:182-7.

Ikeno Y, Bronson RT, Hubbard GB, et al. 2003. Delayed occurrence of fatal neoplastic diseases in Ames dwarf mice: correlation to extended longevity. J Gerontol A. Biol Sci Med Sci, 58A:291-6.

Jadresic A, Banks LM, Child DF, et al. 1982. The acromegaly syndrome. Quart J Med, 202:189-204.

Keene DF, Suescun MO, Bostwick MG, et al. 2002. Puberty in male growth hormone receptor gene disrupted mice. $J$ Androl, 23:661-8.

Kinney BA, Coschigano KT, Kopchick JJ, et al. 2001a. Evidence that ageinduced decline in memory retention is delayed in growth hormone resistant GH-R-KO (Laron) mice. Physiol Behav, 72:653-60.

Kinney BA, Meliska CJ, Steger RW, et al. 2001b. Evidence that Ames dwarf mice age differently from their normal siblings in behavioral and learning and memory parameters. Horm Behav, 39:277-84.

Krzisnik C, Kolacio Z, Battelino T, et al. 1999. The "Little People" of the island of Krk - revisited. Etiology of hypopituitarism revealed. J Endo Gene, 1:9-19.
Kuwahara S, Kesuma Sari D, Tsukamoto Y, et al. 2004. Age-related changes in growth hormone (GH)-releasing hormone and somatostatin neurons in the hypothalamus and in GH cells in the anterior pituitary of female mice. Brain Res, 1025:113-22.

Lamberts SWJ, van den Beld AW, van der Lel A-J. 1997. The endocrinology of aging. Science, 278:419-24.

Laron Z. 2005. Do deficiencies in growth hormone and insulin-like growth factor-1 (IGF-1) shorten or prolong longevity? Mech Ageing Dev, 126:305-7.

Littman AJ, White E, Kristal AR. 2007. Anthropometrics and prostate cancer risk. Am J Epidemiol, 165:1271-9.

Liu H, Bravata DM, Olkin I, et al. 2007. Systematic review: the safety and efficacy of growth hormone in the healthy elderly. Ann Intern Med, 146:104-15.

Liu J-L, Coschigano KT, Robertson K, et al. 2004. Disruption of growth hormone receptor gene causes diminished pancreatic islet size and increased insulin sensitivity in mice. Am J Physiol Endocrinol Metab, 287:E405-13.

Maggio M, Ble A, Ceda GP, et al. 2006. Decline in insulin-like growth factor-1 levels across adult life span in two large population studies. J Gerontol A Biol Sci Med Sci, 61:182-3.

Masoro EJ. 2001. Dietary restriction: An experimental approach to the study of the biology of aging. In: Masoro EJ, Austad SN (editors). Handbook of The Biology of Aging. Fifth Edition. San Diego: Academic Press, pp. 396-420.

Menezes Oliveira JL, Marques-Santos C, Barreto-Filho JA, et al. 2006. Lack of evidence of premature atherosclerosis in untreated severe isolated growth hormone $(\mathrm{GH})$ deficiency due to a GH-releasing hormone receptor mutation. J Clin Endocrinol Metab, 91:2093-9.

Miller RA, Harper JM, Galecki A, et al. 2002. Big mice die young: early life body weight predicts longevity in genetically heterogeneous mice. Aging Cell, 1:22-9.

Orme SM, McNally RJQ, Cartwright RA, et al. 1998. Mortality and cancer incidence in acromegaly: a retrospective cohort study. J Clin Endocrinol Metab, 83:2730-4.

Papadakis MA, Grady D, Black D, et al. 1996. Growth hormone replacement in healthy older men improves body composition but not functional ability. Ann Intern Med, 124:708-16.

Parsons JA, Bartke A, Sorenson RL. 1995. Number and size of islets of Langerhans in pregnant, human growth hormone-expressing transgenic, and pituitary dwarf mice: Effect of lactogenic hormones. Endocrinology, 136:2013-21.

Partridge L, Gems D, Withers, DJ. 2005. Sex and death: What is the connection? Cell, 120:461-72.

Patronek GJ, Waters DJ, Glickman LT. 1997. Comparative longevity of pet dogs and humans: implications for gerontology research. $J$ Gerontol A Biol Sci Med Sci, 52A:B171-8.

Ramsey MM, Weiner JL, Moore TP, et al. 2004. Growth hormone treatment attenuates age-related changes in hippocampal short-term plasticity and spatial learning. Neuroscience, 129:119-27.

Roberts RC. 1961. The lifetime growth and reproduction of selected strains of mice. Heredity, 16:369-81

Rollo CD. 2002. Growth negatively impacts the life span of mammals. Evol Dev, 4:55-61.

Rudman D, Feller AG, Nagraj HS, et al. 1990. Effects of human growth hormone in men over 60 years old. N Engl J Med, 323:1-6.

Sacca L, Cittadini A, Fazio S. 1994. Growth hormone and the heart. Endocr Rev, 15:555-73

Sacca L, Napoli R, Cittadini A. 2003. Growth hormone, acromegaly, and heart failure: an intricate triangulation. Clin Endocrinol, 59:660-71.

Samaras TT, Storms LH. 2002. Secular growth and its harmful ramifications. Med Hypotheses, 58:93-112.

Samaras T. 2007. Human body size and the laws of scaling: Physiological, performance, growth, longevity and ecological ramifications. New York: Nova Science Publishers, Inc.

Schnaider Beeri M, Davidson M, Silverman JM, et al. 2005. Relationship between body height and dementia. Am J Geriatr Psychiatry, 13:116-23. 
Sell C, Lorenzini S. 2007. Aging in IGF-1 hypomorphic mice, The American Aging Association 36th Annual Meeting. American Aging Association, San Antonio, TX.

Selman C, Lingard S, Choudhury AI, et al. 2008. Evidence for lifespan extension and delayed age-related biomarkers in insulin receptor substrate 1 null mice. FASEB, 22:807-18.

Shalet SM, Toogood A, Rahim A, et al. 1998. The diagnosis of growth hormone deficiency in children and adults. Endocr Rev, 19:203-23.

Shechter M, Ginsberg S, Scheinowitz M, et al. 2007. Obese adults with primary growth hormone resistance (Laron Syndrome) have normal endothelial function. Growth Horm IGF Res, 17:165-70.

Shevah O, Laron Z. 2007. Patients with congenital deficiency of IGF-I seem protected from the development of malignancies: a preliminary report. Growth Horm IGF Res, 17:54-7.

Shimokawa I, Higami Y, Utsuyama M, et al. 2002. Lifespan extension by reduction of the growth hormone-insulin-like growth factor-1 axis: relation to caloric restriction. Am J Pathol, 160:2259-65.

Silberberg R. 1972. Articular aging and osteoarthrosis in dwarf mice. Pathol Microbiol (Basel), 38:417-30.

Sonntag EW, Steger RW, Forman JL, et al. 1980. Decreased pulsatile release of growth hormone in old male rats. Endocrinology, 107:1875-9.

Sonntag WE, Carter CS, Ikeno Y, et al. 2005a. Adult-onset growth hormone and insulin-like growth factor I deficiency reduces neoplastic disease, modifies age-related pathology, and increases life span. Endocrinology, 146:2920-32.
Sonntag WE, Ramsey M, Carter CS. 2005b. Growth hormone and insulinlike growth factor-1 (IGF-1) and their influence on cognitive aging. Ageing Res Rev, 4:195-212.

Suh Y, Atzmon G, Cho M-O, et al. 2008. Functionally significant insulinlike growth factor I receptor mutations in centenarians. Proc Natl Acad Sci U S A, 105:3438-42.

Taguchi A, Wartschow LM, White MF. 2007. Brain IRS2 signaling coordinates life span and nutrient homeostasis. Science, 317:369-72.

Tretli S. 1989. Height and weight in relation to breast cancer morbidity and mortality. A prospective study of 570,000 women in Norway. Int J Cancer, 44:23-30.

von Werder K. 1999. The somatopause is no indication for growth hormone therapy. $J$ Endocrinol Invest, 22:137-41.

Zaczek DJ, Hammond JM, Suen L, et al. 2002. Impact of growth hormone resistance on female reproductive function: New insight from growth hormone receptor knockout mice. Biol Reprod, 67:1115-24.

Zhou Y, Xu BC, Maheshwari HG, et al. 1997. A mammalian model for Laron syndrome produced by targeted disruption of the mouse growth hormone receptor/binding protein gene (the Laron mouse). Proc Nat Acad Sci U S A, 94:13215-20. 
